\title{
3D DOCUMENTATION OF GLOBAL HISTORIC SITES: THE 'SCOTTISH TEN' PROJECT AND ITS APPLICATIONS FOR CULTURAL HERITAGE
}

\author{
L. Wilson $^{\mathrm{a}^{*}}$, A. Rawlinson ${ }^{\mathrm{b}}$, D.S. Mitchell ${ }^{\mathrm{a}}$, D.K. Pritchard ${ }^{\mathrm{b}}$ and H.C. McGregor ${ }^{\mathrm{a}}$ \\ ${ }^{a}$ Historic Scotland, Longmore House, Edinburgh, EH9 1SH, Scotland - (lyn.wilson, david.mitchell, \\ chris.mcgregor)@scotland.gsi.gov.uk \\ ${ }^{b}$ Digital Design Studio, Glasgow School of Art, The Hub, Pacific Quay, Glasgow, G51 1EA, Scotland - (a.rawlinson, \\ d.pritchard)@gsa.ac.uk
}

\begin{abstract}
KEYWORDS: Scottish Ten, cultural heritage, terrestrial laser scanning, georeferencing, recording, analysis, monitoring, visualisation.

ABSTRACT: The Scottish Ten project seeks to digitally document World Heritage Sites in Scotland and culturally significant international heritage sites, using technologies such as terrestrial laser scanning, aerial LiDAR, high resolution photography, digital photogrammetry, high-accuracy GPS and digital total stations. The project has numerous aims, centering around conservation, cultural heritage management, promoting Scotland's technical and scientific expertise and Scottish cultural connections. This paper focuses on the recent 3D survey work in the Heart of Neolithic Orkney World Heritage Site in Scotland. Two principal sites, Skara Brae and Maeshowe, are described, the methodologies undertaken and the results so far. Aside from generating accurate survey records, data will be utilised for analysis and interpretation, monitoring, visualisation and numerous other purposes. Although the data is still at the early stages of processing, the paper highlights the significant potential of $3 \mathrm{D}$ survey for understanding and managing the Heart of Neolithic Orkney and the benefits of 3D survey for cultural heritage applications in general.
\end{abstract}

\section{INTRODUCTION}

The Scottish Ten is an ambitious global project to fully digitally document Scotland's five UNESCO world heritage sites and five international heritage sites (www.scottishten.org). Conceived in 2009, the project is funded by the Scottish Government and will run for five years to completion. A range of digital technologies is involved, including terrestrial laser scanning, aerial LiDAR, high-resolution photography, digital photogrammetry, high-accuracy GPS and digital total stations.

The Scottish sites are; the Old and New Towns of Edinburgh, New Lanark $18^{\text {th }}$ Century Mill Village, St Kilda islands, the Antonine Wall (the most northerly frontier of the Roman Empire) and the Heart of Neolithic Orkney. The international sites known to date are; Mount Rushmore National Memorial, USA and Rani Ki Vav Royal Step Well, India. Others will be confirmed in due course. To date, on-site work for New Lanark, Neolithic Orkney and Mount Rushmore has been completed.

The project has numerous broad aims:

- To accurately record important historical sites for the benefit of future generations in Scotland and overseas.

- To share and disseminate Scottish technical expertise and foster international collaboration.

- To provide digital media to site managers to better care for the heritage resource.

- To recognise international Scottish cultural connections.

The Centre for Digital Documentation and Visualisation (CDDV) is a limited liability partnership between Historic Scotland and the Digital Design Studio at Glasgow School of Art and has been established as a vehicle to deliver the Scottish Ten. The point cloud data will be hosted with CyArk (www.cyark.org) when complete.

\section{CASE STUDY}

2.1 3D Digital Documentation of The Heart of Neolithic Orkney and Cultural Heritage Applications

The World Heritage Site in Orkney covers a unique cultural landscape, dating back approximately 5,000 years. One of the main sites within this landscape is Skara Brae, a Neolithic village comprising individual domestic housing. It is the best preserved group of prehistoric houses in Western Europe. The chambered tomb at Maeshowe is significant not only as a Neolithic monumental masterpiece and the finest example of its kind in NW Europe, but also for its fantastic collection of $12^{\text {th }}$ century Viking inscriptions, the interior walls being covered with graffiti runes and other carvings. Stone circles and standing stones complete the current World Heritage inscription.

The sites are conserved and managed by Historic Scotland, the Scottish government agency charged with safeguarding the nations heritage and promoting its enjoyment and understanding for future generations. In August 2010, the Centre for Digital Documentation and Visualisation working in partnership with Historic Scotland undertook a comprehensive 3D survey of all sites within the World Heritage zone.

\subsection{Objectives}

The objectives of the project were numerous:

- Generate a highly accurate digital 3D survey.

- Develop an interpretation and education tool, based on virtual reality reconstructions.

- Visual aid to understanding construction phases of structures. 
- Conservation aid.

- Condition monitoring.

- Coastal erosion monitoring.

- $\quad$ Promote public engagement and partnership working.

- Allow virtual access to remote and inaccessible sites.

- Develop and promote virtual tourism.

\section{METHODOLOGY}

Airborne LiDAR data and ortho-rectified photography was collected for the entire World Heritage zone at $0.5 \mathrm{~m}$ resolution with imagery in 24-bit colour.

Terrestrial laser scanning (TLS) is now a well-established method for large-scale heritage documentation (e.g. Bedford and Papworth 2009, Lerma et al. 2010, Wilson et al. 2010). TLS was therefore the principal survey technique used at each main site, and was carried out at $5-10 \mathrm{~mm}$ resolution using a combination of time-of-flight and phase-based scanners (Leica ScanStation 2 and C10 and Leica HDS6100). Closed-loop traverses provided an accuracy of $\pm 2 \mathrm{~mm}$ for each site. Additional scans were registered to the primary point cloud using high definition surveying (HDS) targets. TLS data collection was augmented by digital total station surveys (Leica TCRA 1105+) and GPS data collection (Leica GNSS 1200+ receiver) to fully georeference the point clouds. High-resolution $360^{\circ}$ panoramic photography was obtained from each scan location using a Nikon D3X camera with Nikon $12 \mathrm{~mm}$ lens and a Nodal Ninja mount to enable photo-mapping directly onto the point cloud.

Triangulation laser scanners were used for sub-mm close-range capture of carvings and inscriptions (Hexagon Romer arm with Perceptron Scanworks v5 laser scanner and Konica-Minolta Vivid 9i).

Data processing is currently in progress on this project, but some initial results are given here. The project utilises Leica Cyclone, Leica GeoOffice, TheoLt (using the TheoNetAdjust functionality), Polyworks and 3D Studio Max software packages. All datasets will be combined and used within a GIS environment (using ArcGIS).

\section{RESULTS AND DISCUSSION}

\subsection{Skara Brae}

Skara Brae village is situated in very close proximity to the North Sea. It consists of a complex system of small houses interlinked by passageways and tunnel systems (Figure 1). The site has been fully documented in 3D and georeferenced, with an overall point cloud accuracy of $\pm 6 \mathrm{~mm}$.

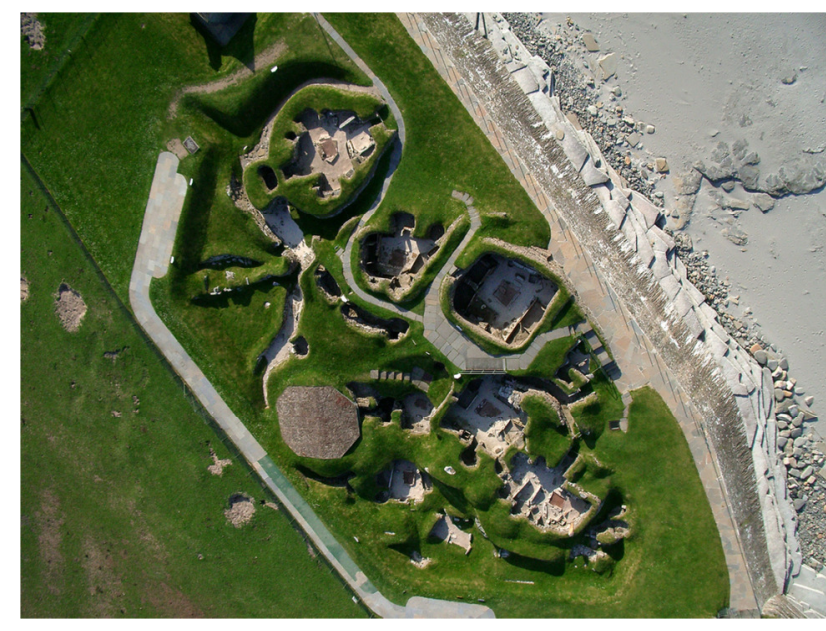

Figure 1. Aerial photo of Skara Brae, showing close network of houses and proximity of site to coastline (C) P. and M. Snodin 2009.

\section{Recording}

Generating an accurate survey record for the site was an important priority for Historic Scotland. Since the village is composed of numerous low and narrow passages, some very difficult to access, the site has never been mapped in its entirety. The team were able to position the Leica HDS6100 and C10 scanners in crevices and passageways too small for a person to fit, thus obtaining a comprehensive map (Figure 2).

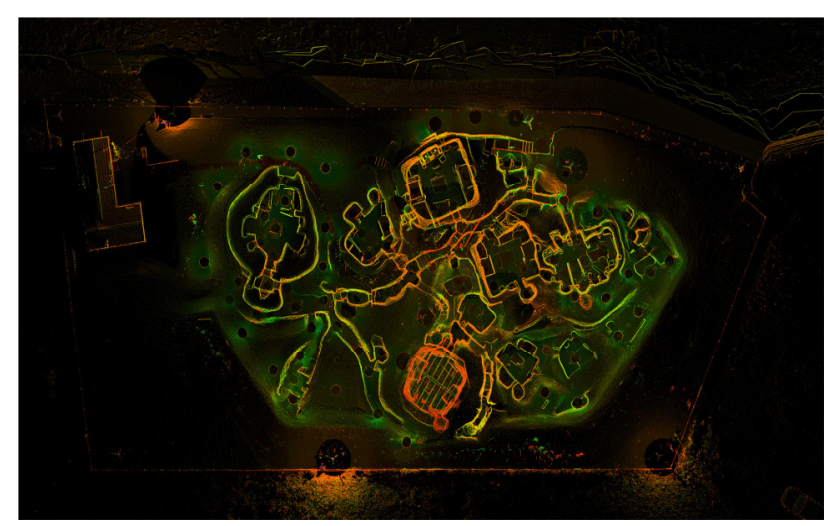

Figure 2. Point cloud showing plan view of Skara Brae village, coloured by intensity values (C) CDDV 2010.

The registered point cloud data will be utilised in facilities management of the site, allowing accurate dimensions to be taken and assisting with planning and implementation of ongoing conservation and maintenance works.

\section{Monitoring}

Coastal erosion is a critical heritage management issue at this site. A defensive sea wall has been installed and TLS included recording of this wall from the shoreline (Figure 3). Permanent survey markers were installed for the TLS work, allowing for regular repeat scans and monitoring of coastal erosion. 


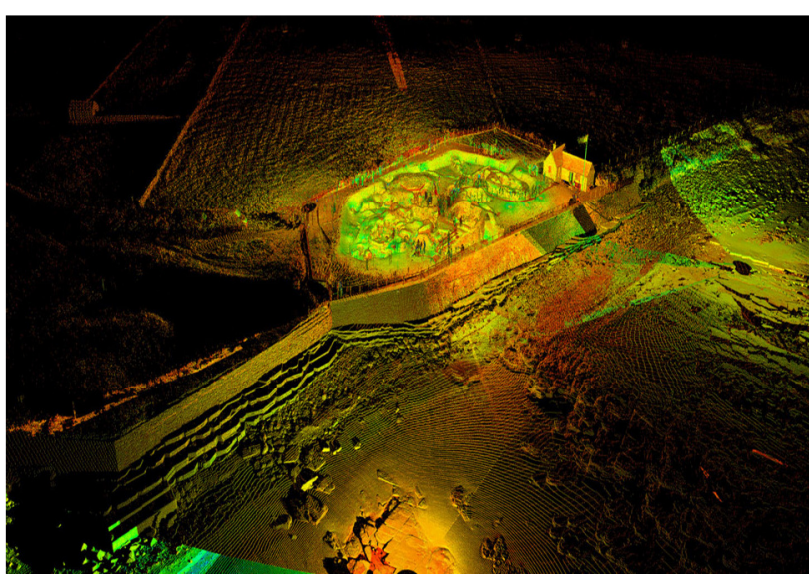

Figure 3. Sea wall defences visible in TLS data from Skara Brae, as recorded from the shoreline and coloured by intensity values $\odot$ CDDV 2010.

This initial dataset will act as a baseline and subsequent recording will be carried out at defined time intervals. Digitisation of the sea wall defences will be of assistance in quantifying any future erosion (Figure 4). Conservation intervention will take place when and where necessary.

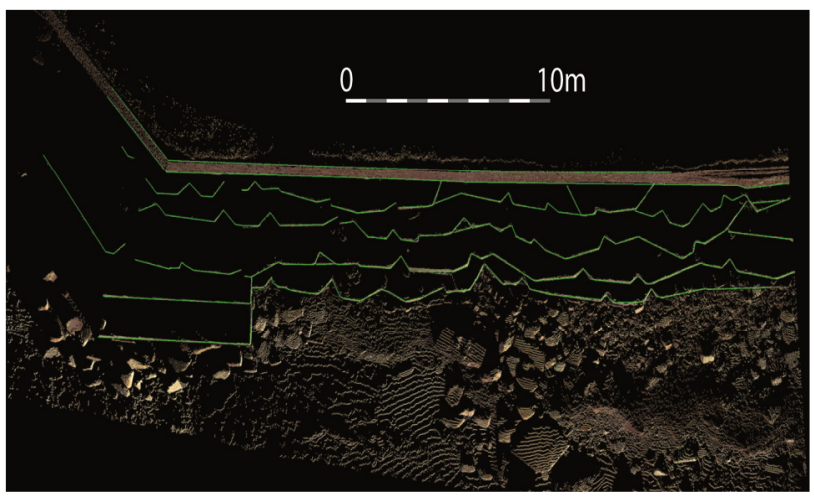

Figure 4. Digitisation of sea wall defences from TLS data (C) CDDV 2011.

Airborne LiDAR data will also be useful for monitoring longterm and large-scale coastal erosion. The coastal topographic data collected for this project will serve as a baseline. LiDAR data in XYZ format was meshed to form a polygonal model, then high resolution aerial photography was UVW mapped onto this surface, as shown in Figure 5. The model was then rendered using a direct shadow casting light to emphasise topological change in the terrain.

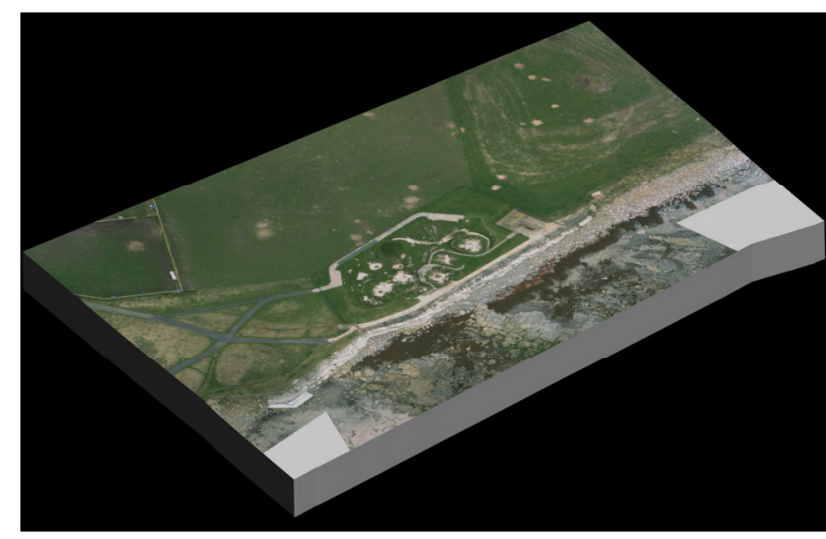

Figure 5. Model from airborne LiDAR data showing site and coastal defenses at Skara Brae (C) CDDV 2011.

Remote sensing techniques such as LiDAR are well-regarded methodologies for archaeological site or feature identification (e.g. Crutchley 2010, Devereux et al. 2005, 2008). LiDAR data will therefore be interrogated with a view to identifying potential new archaeological sites within the World Heritage Zone. The area is extremely rich in Neolithic and later heritage and much undoubtedly remains to be discovered.

\section{Visualisation}

Virtual reconstruction of the village, based on the accurate 3D survey data will enable visitors, both on site and remote, to view the village in its original appearance and to observe different construction phases. House 7 within the village is the best preserved and to maintain this condition, the house has been roofed over and visitor access prohibited. The TLS data and its interpretative visualisation will allow virtual access to this space without compromising conservation and maintenance plans (Figures 6, 7). High-resolution photography will be mapped onto the model surfaces to create virtual tours of the as-built structures, while virtual reconstructions will make use of archaeological evidence.

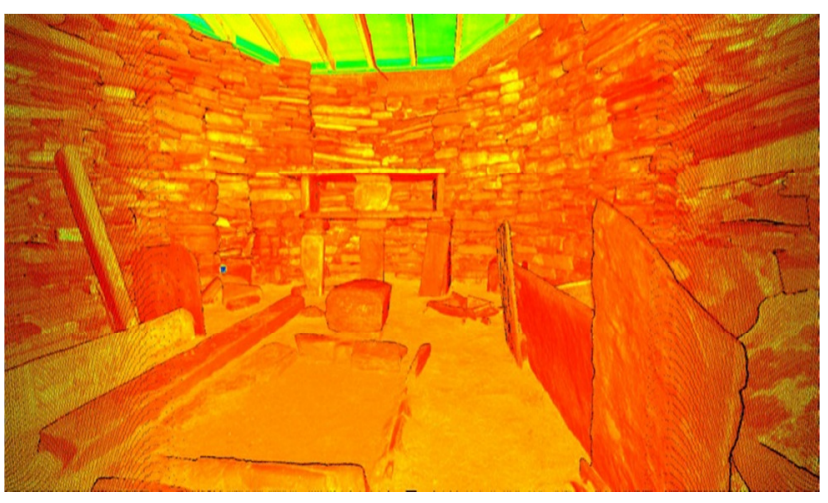

Figure 6. Point cloud of House 7 interior at Skara Brae, coloured by intensity values (C) CDDV 2010. 


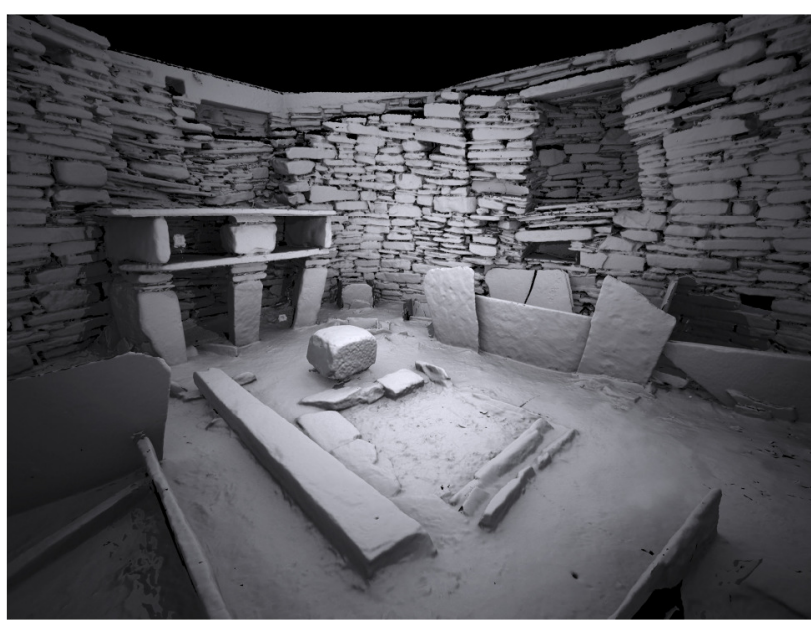

Figure 7. Meshed point cloud data showing interior of House 7 at Skara Brae. The mesh was created with an interpolation step of $8 \mathrm{~mm}$ and contains 6 million polygons. The model was rendered in 3D Studio Max using the VRAY rendering engine with a physical camera $\odot$ CDDV 2011.

\subsection{Maeshowe}

Maeshowe chambered tomb (Figure 8) is covered by a protective grassy mound which requires ongoing conservation and maintenance to prevent water ingress into the tomb itself. The interior consists of a low passageway leading to an interior central chamber, with three smaller chambers leading from it.

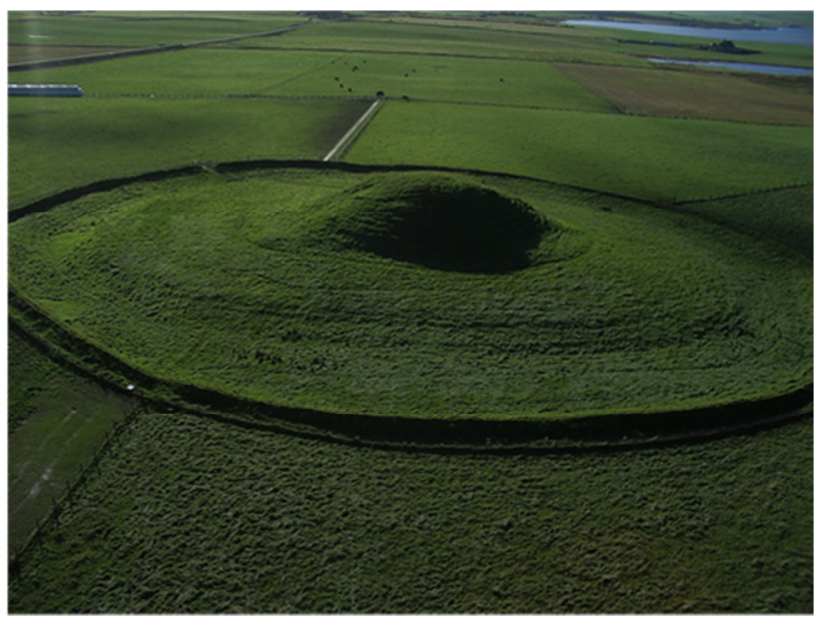

Figure 8. Maeshowe chambered tomb, as seen from the air (C) Crown Copyright 2008.

\section{Recording}

The site has been fully documented inside and out in 3D and georeferenced, with an overall point cloud accuracy of $\pm 6 \mathrm{~mm}$. Figure 9 shows a cross-section through the registered point cloud, which ties interior and exterior scans together. TLS allows a unique visualisation through the tomb.

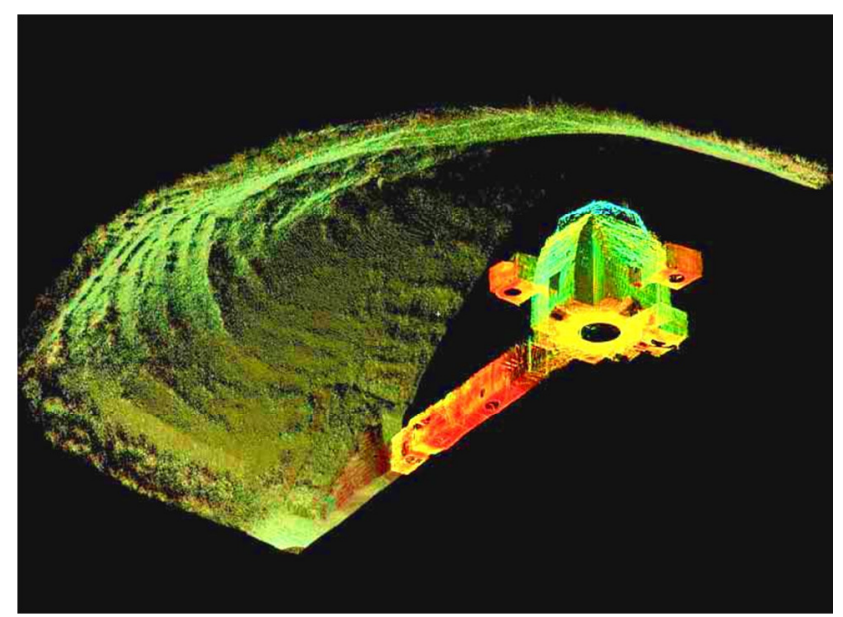

Figure 9. Cross-section through point cloud of Maeshowe chambered tomb, coloured by intensity values (C) CDDV 2010.

\section{Analysis}

Accurate CAD drawings have been produced from the point cloud data to assist conservation architects with ongoing conservation and maintenance work. Section drawings allow for analysis of the structure in detail (Figure 10).

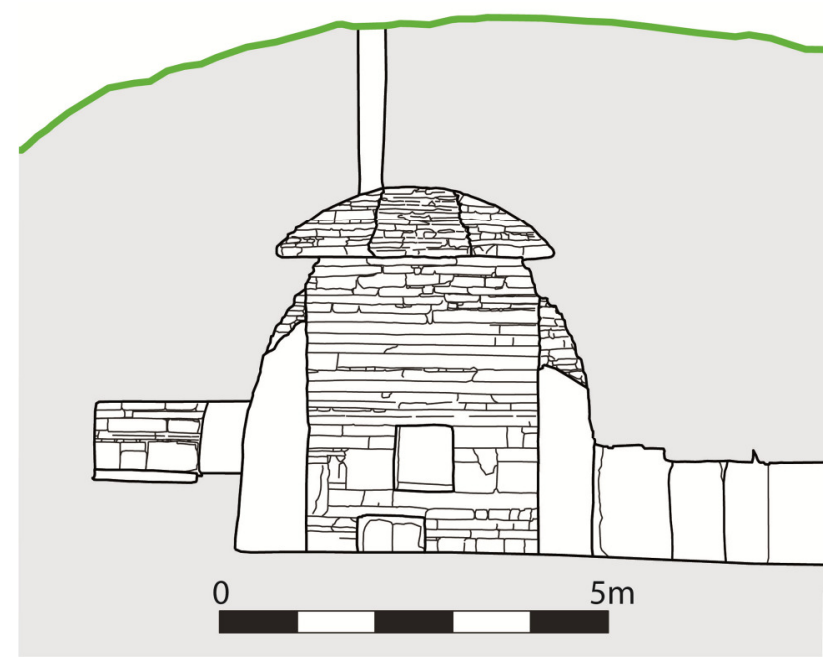

Figure 10. CAD section drawing through Maeshowe chambered tomb in a NE-SW orientation (c) CDDV 2011.

\section{Monitoring}

As previously mentioned, the interior of Maeshowe tomb is adorned with a rich collection of Neolithic carvings and $12^{\text {th }}$ Century Viking runic inscriptions. Historically, there was some concern over water ingress to the monument and the possibility of clays washing out from the sandstone. This could potentially have put the inscriptions at risk. Remedial conservation work was undertaken by Historic Scotland as soon as the problem was identified, but a monitoring programme was implemented nevertheless.

The carvings and inscriptions were scanned at very high resolution $(0.1 \mathrm{~mm})$ using a Perceptron v5 scanner (Figure 11). 
Polygonal models were produced from the resultant point clouds using Polyworks software (Figure 12).

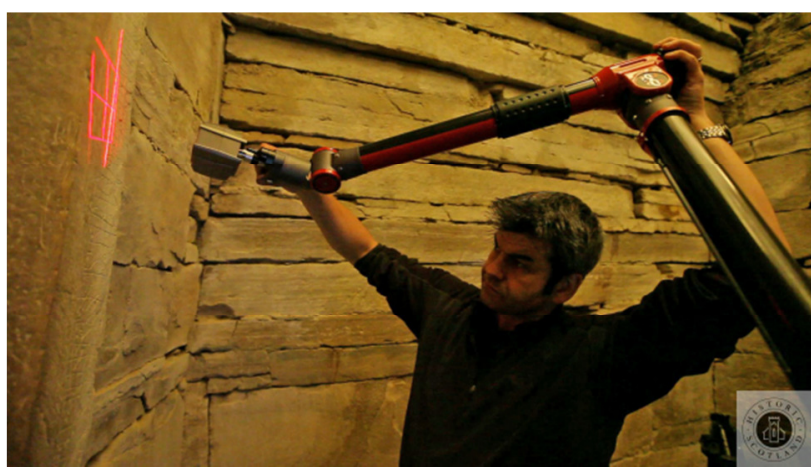

Figure 11. Close-range recording of Viking runic inscriptions inside Maeshowe chambered tomb using a Perception Scanworks v5 laser scanner (C) Crown Copyright 2010.

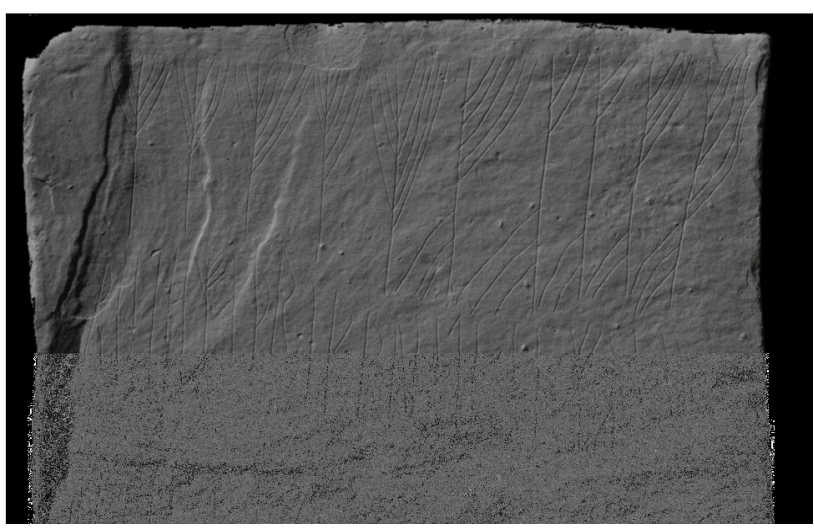

Figure 12. Meshed point cloud data from Viking runic inscription within Maeshowe chambered tomb () CDDV 2010. The inscription reads: "These runes were carved by the man most skilled in runes in the western ocean" (Ashmore 2000).

The 2010 laser scan data can be compared with a previous scanning epoch in 2003, which generated baseline data for each inscription. Using Polyworks IM Inspect module, quantitative error maps are generated from the two datasets, highlighting any potential areas of risk to the delicate stonework and accurately mapping any areas of accretion or erosion. Figure 13 shows one such error map for a section of the inscription shown in Figure 12.

The error map shows very little change (either erosion or accretion) has occurred during the seven years between scans. The measurable deviation is within the tolerance that conservators at Historic Scotland will allow. At this time, no conservation treatments are considered necessary. The monitoring programme will continue at regular intervals.

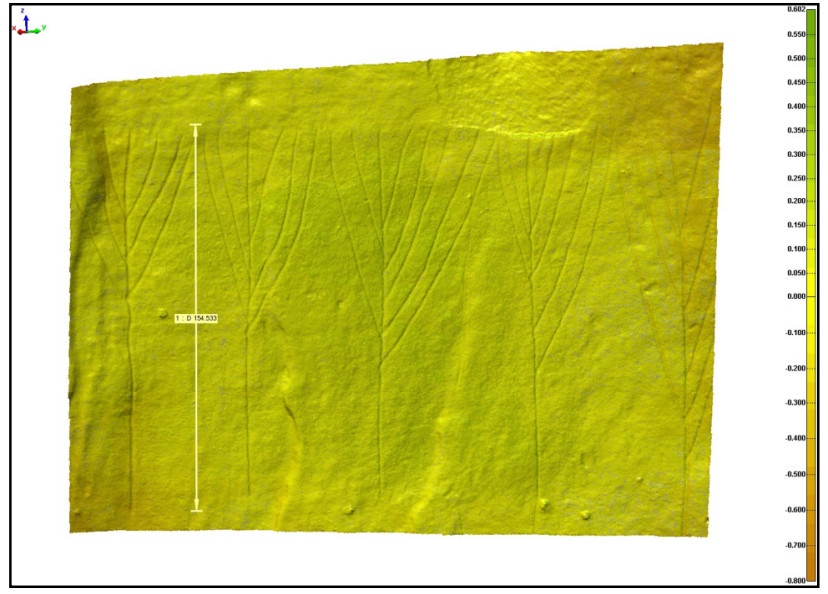

Figure 13. Quantitative error map from Maeshowe runic inscription, comparing high resolution laser scan data from 2003 and 2010 scanning epochs. Yellow indicates no erosion or accretion. The scale measures deviation from $-0.800 \mathrm{~mm}$ to $+0.602 \mathrm{~mm}$ () CDDV 2011.

\section{Visualisation}

Visitor numbers to Maeshowe are restricted to promote preservation of the site and so the potential for virtual reality tours using photo-textured mesh data, such as is shown in Figure 14, will be explored to allow remote access and to promote the site on a global level. High quality photo-textured animations will be generated to enhance the virtual visitors experience.

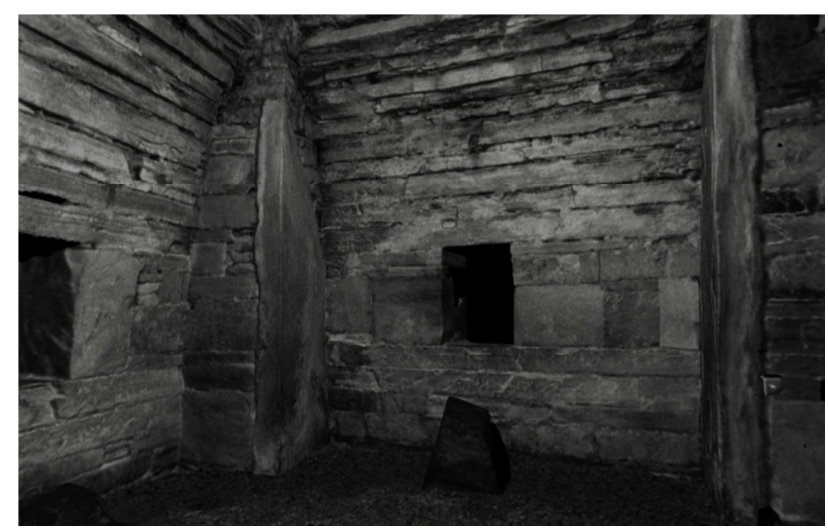

Figure 14. Meshed point cloud data showing interior of Maeshowe chambered tomb. The mesh was generated from a single scan with an interpolation step of $6 \mathrm{~mm}$ and contains 12 million polygons. It shows intensity values from the scanner in greyscale () CDDV 2010.

\section{CONCLUSIONS}

This paper highlights some early interpretation of the 3D digital survey data collected from the Heart of Neolithic Orkney, although there is considerably more work to be completed to maximise the potential of the information. In particular, photomapping of high resolution imagery onto meshed models for the creation of virtual reality animations will be an important next step. This will allow virtual access to remote or inaccessible sites and for the development of virtual tourism. Virtual reconstructions will be created, based on the TLS data and 
archaeological evidence to formulate interpretation and education tools. There is also the potential for integration of the TLS and LiDAR data within a GIS environment and combining this with extensive geophysical data which exists for the area. This will allow visualisation of the Orcadian landscape both above and below ground level.

Although still in its initial stages, the Neolithic Orkney case study illustrates the range of cultural heritage applications directly emanating from The Scottish Ten project data. Overall, the Scottish Ten provides an ideal platform to promote 3D digital documentation of historic sites on a global scale and emphasise the practical benefits of the technology for both heritage management bodies and for the interested public.

\section{REFERENCES}

3D Studio Max software. http://usa.autodesk.com (accessed 2 Feb. 2011).

ArcGIS software. http://www.esri.com (accessed 2 Feb. 2011).

Ashmore, P., 2000. Maeshowe World Heritage Site. Historic Scotland, Edinburgh, p. 14.

Bedford, J. and Papworth, H. (editors), 2009. Measured and Drawn: Techniques and Practice for the Metric Survey of Historic Buildings (Second Edition). English Heritage, Swindon.

Crutchley, S., 2010. The light fantastic: Using airborne LiDAR in archaeological survey, in Wagner, W., Szekely, B. (editors): ISPRS TC VII Symposium - 100 Years ISPRS, Vienna, Austria, July 5-7, 2010, International Archives of the Photogrammetry, Remote Sensing and Spatial Information Sciences, Vol. XXXVIII, Part 7B, pp. 160-164.

Devereux, B.J., Amable, G.S. and Crow, P., 2008. Visualisation of LiDAR terrain models for archaeological feature detection. Antiquity 82, pp. 470-479.

Deveruex, B.J., Amable, G.S., Crow, P. and Cliff, A.D., 2005. The potential of airborne LiDAR for detection of archaeological features under woodland canopies. Antiquity 79, pp. 648-660.

Innovmetric Polyworks software. http://www.innovmetric.com (accessed 2 Feb. 2011).

Leica Cyclone and GeoOffice software. http://www.leicageosystems.co.uk (accessed 2 Feb. 2011).

Lerma, J.L., Navarro, S., Cabrelles, M. and Villaverde, V., 2010. Terrestrial laser scanning and close range photogrammetry for 3D archaeological documentation: The Upper Palaeolithic Cave of Parpallo as a case study. Journal of Archaeological Science 37, pp. 499-507.

TheoLt software. http://www.theolt.com (accessed 2 Feb. 2011).

Wilson, L., Mitchell, D.S., Davey, A. and Pritchard, D., 2010. Digital Documentation of Historic Ferrous Metal Structures: 3D Laser Scanning as a Conservation Tool, in Mardikian, P., Chemello, C., Watters, C. and Hull, P. (editors): Metal 10, International Conference on Metal Conservation. Interim
Meeting of the International Council of Museums Committee for Conservation Metal Working Group. October 11-15 2010, Charleston, USA, Clemson University Press: Charleston: 279286.

\section{ACKNOWLEDGMENTS}

Historic Scotland team: James Hepher, Colin Muir, Maureen Young, Alan Simpson, Rob Nuttall, Lyal Purves.

Digital Design Studio team: Jared Benjamin. 